\title{
Tentorial haematoma in a newborn
}

\author{
Mustafa Kemal Demir • Ercument Unlu
}

Received: 12 October 2008 /Revised: 31 December 2008 / Accepted: 7 January 2009 / Published online: 7 February 2009

(C) Springer-Verlag 2009

A term infant with normal Apgar scores developed seizures 1 day after a prolonged vaginal delivery. On the second day of life MRI demonstrated a haematoma within the leaves of the tentorium that was high signal on T1-W images (Fig. 1) and low-signal on T2-W images (Fig. 2). There were also bilateral convexity and parafalcine subdural haematomas. She was transferred to the ICU for management and observation. Extensive laboratory studies were normal. She remained in a stable condition for 2 weeks prior to discharge.

Tentorial haematomas in term neonates are rare. Birth trauma, coagulation disorders and hypoxia are the main causes. Disruption of the tentorium with rupture of bridging

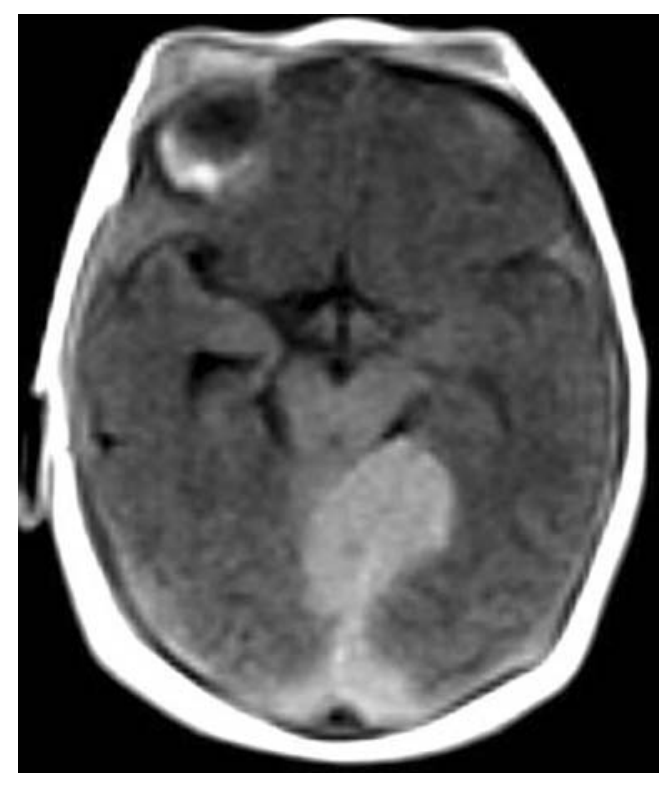

Fig. 1 Axial T1-W MR image

M. K. Demir $(\bowtie) \cdot$ E. Unlu

Radiology Department, Trakya University School of Medicine,

11 kisim, Yasemin apt, D:Blok. D:35,

Ataköy, Istanbul 34158, Turkey

e-mail: demirkemal@superonline.com

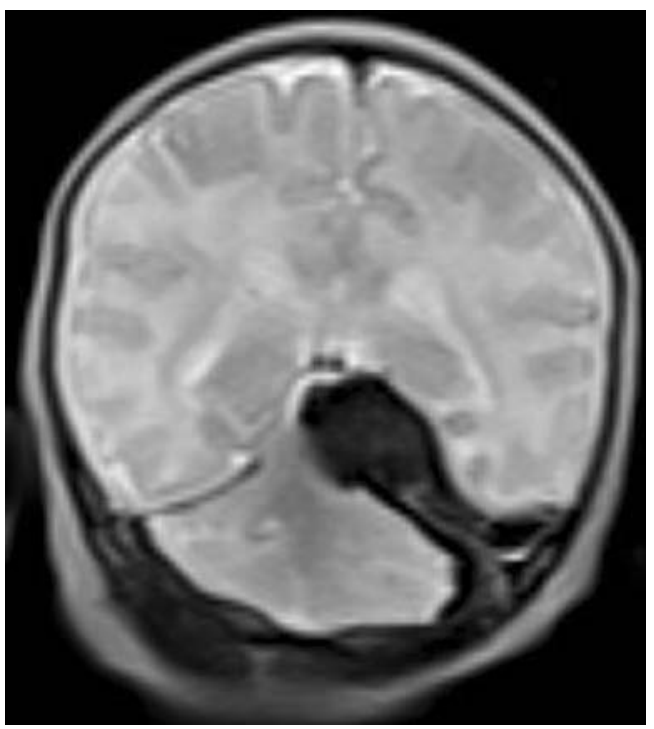

Fig. 2 Coronal T2-W MR image

veins or laceration of the adjacent venous sinuses may result in tentorial haematoma [1]. CT or MRI confirms the diagnosis.

The treatment strategy depends on the patient's clinical state. Surgical treatment is preferable when there are signs of brainstem compression such as apnoea, bradycardia or hypotension, to prevent a fatal outcome. Acute obstructive hydrocephalus is a further valid indication for surgery. However, conservative management may be appropriate in patients without significant neurological impairment [2].

\section{References}

1. Usul H, Karaarslan G, Cakir E et al (2005) Conservative management of spontaneous posterior fossa subdural hematoma in a neonate. J Clin Neurosci 12:196-198

2. Perrin RG, Rutka JT, Drake JM et al (1997) Management and outcomes of posterior fossa subdural hematomas in neonates. Neurosurgery 40:1199-1200 